\title{
ARTICLE
}

\section{Engaging parents in positive education: Results from a pilot program}

\author{
Karina Dubroja $\cdot$ Meredith O'Connor $\cdot$ Vicki Mckenzie
}

\begin{abstract}
Positive education aims to contribute to the optimal functioning of students, staff, and school communities. Parents play a vital role in school communities, and finding effective ways to engage parents with positive education is therefore critical. This small-scale pilot study aimed to provide preliminary insights into the impact of a 3-day intensive positive education program for parents, which focused on teaching positive psychology strategies, such as gratitude and use of character strengths, to the parent population. A mixed methodology non-randomized control group design was used to assess pre- to post-intervention change in 24 intervention participants and 16 waitlist control participants. An online survey assessed parents' mental health and wellbeing, knowledge and use of character strengths, feelings of connection with the school, and beliefs about child wellbeing. Results revealed significant increases in parental wellbeing and parent-school connection among the intervention participants, as compared to controls. Qualitative results indicated that parents also perceived a positive impact on their communication with their child. Overall, the study findings provide promising preliminary evidence for the benefits of strategically engaging parents in positive education. Replication is now needed in further larger-scale studies.
\end{abstract}

Keywords: positive education, parent-school relationship, school community; whole-school approach

\section{Introduction}

Positive education is a whole-school mental health promotion strategy that aims to cultivate wellbeing in students, staff and the school community (Norrish, Williams, O'Connor, \& Robinson, 2013). Parents are important stakeholders in school communities that have yet to be strategically targeted within positive education. This is despite emerging evidence suggesting that the wellbeing of parents and their children are interrelated (Hoy, Suldo, \& Mendez, 2013; Park \& Peterson, 2006), and that students tend to benefit when parents feel a strong connection to their child's school (Siddall, Huebner, \& Jiang, 2013; Suldo, McMahan, Chappel, \& Loker, 2012). Engaging parents in positive education could therefore be a promising extension of mental health promotion efforts within school communities.

One approach that has been piloted is to provide parents with the opportunity to attend intensive training in positive psychology interventions (PPIs), which have been previously validated in adult samples (Sin \& Lyubomirsky, 2009). As applied to parents, training in and subsequent use of PPIs may provide a means of reinforcing student learning by allowing for additional role modelling and consistent language across the home and school settings. This study aimed to provide preliminary insights from a small sample into the impact of parent 
training in PPIs, in order to inform: 1) further development of strategies to meaningfully engage parents in positive education programs, and 2) future larger-scale evaluation efforts.

\section{Positive education}

The last few decades have seen a growing recognition of the need for schools to focus on the growth of the whole child, including social, emotional and moral aspects, in addition to traditional academic learning (Waters, 2011; White, 2011). While traditional academic learning is important, children's wellbeing is also essential for positive school functioning and is a highly valued outcome by children, parents, and school communities (Seligman, Ernst, Gillham, Reivich, \& Linkins, 2009). The role of student wellbeing is now recognised in the Australian National Curriculum for schools, which asserts that personal and social capability is the basis for learning and participating in society (Australian Curriculum Assessment and Reporting Authority, 2013). As well as supporting student learning, preventative mental health strategies may also provide an indirect means of addressing the alarmingly high rates of mental health difficulties experienced by Australian children and young people (Kvalsvig, O'Connor, Redmond, \& Goldfeld, 2014).

Responding to this increased interest in student wellbeing, positive education seeks to combine positive psychology principles with best practice teaching and educational paradigms to promote optimal development and wellbeing in the school community (Norrish et al., 2013). Approaches to implementing positive education programs differ, but generally include explicit and implicit teaching in combination with school-wide practices targeting domains such as emotional regulation, engagement, accomplishment of meaningful goals, purpose through contribution to the community, social skills for healthy relationships, and health promoting behaviours (Norrish et al., 2013). Following this defintion, the current paper considers an individual to have a high level of wellbeing when they are thriving in these domains. As a wholeschool approach, staff are also trained in using positive education skills, and positive education principles are integrated through organizational structures and policies. Research to date, though limited, suggests that positive education programs may yield benefits to student wellbeing (Norrish \& O'Connor, 2015; Shoshani \& Steinmetz, 2013; Vella-Brodrick, Rickard, \& Chin, 2014).

\section{The role of parents in promoting student wellbeing}

Alongside schools, the family environment is another major influence on the psychosocial development of children and adolescents (Bronfenbrenner, 1979). An established evidence base has shown the importance of positive parenting styles to child and adolescent wellbeing (Ehrmantrout, Allen, Leve, Davis, \& Sheeber, 2011; Jaser et al., 2005; O'Connor et al., 2011; Viner et al., 2012). In particular, warm, supportive and accepting parenting behaviours are associated with elevated life satisfaction (Ma \& Huebner, 2008; Schwarz et al., 2011), and continued wellbeing into adulthood (Huppert, Abbott, Ploubidis, Richards, \& Kuh, 2010). In contrast, research has demonstrated associations between harsh and rejecting parenting behaviours and elevated depression and anxiety (Betts, Gullone, \& Allen, 2009; Bruce et al., 2006; Crosby, Drazdowski, \& Ginsburg, 2013; Knappe, Beesdo-Baum, Fehm, Lieb, \& Wittchen, 2012).

Recent work also suggests associations between parent and child wellbeing. For example, Hoy, Suldo and Mendez's (2013) study of 148 children (aged 9-11) and their parents (137 mothers, 109 fathers) showed that maternal gratitude predicted child gratitude, and children's life satisfaction was positively correlated with both maternal and paternal life satisfaction. Casas and colleagues (2012) similarly found a significant albeit modest relationship between parental and child wellbeing. While the correlational nature of these findings prevents causal inferences, they 
are suggestive of a familial transmission of wellbeing from parent to child. Enhancing parents' wellbeing may therefore provide an indirect means of impacting student wellbeing.

As well as parents' relationships with their children, their relationship with the school may also carry implications for their child's wellbeing. Epstein's (1995) model of overlapping spheres of influence emphasises that schools, families, and communities are most effective when they work in partnership with common values. The partnership acts collaboratively to support a child's learning and wellbeing (Epstein, 2011). Supporting this, Siddal, Huebner, and Jiang's (2013) study of 597 adolescents found that family-school interactions predicted adolescents' life satisfaction. In other words, parental involvement at school was a consistent predictor of student wellbeing (Suldo et al., 2012), as well as being strongly associated with their life satisfaction (Danielsen, Samdal, Hetland, \& Wold, 2009). Positive education is therefore likely to be most effective if all key stakeholders, including parents, are engaged with positive education practices, creating a common language and cultural norms across the school community (Norrish et al., 2013).

\section{Positive Education for Parents program}

Geelong Grammar School (GGS) is an independent, Anglican, co-educational, boarding and day school. It is located across four campuses in Victoria, Australia, with over 1,500 students. In 2008, during a 6-month visit by Professor Martin Seligman and with extensive support from a team of international experts, GGS began applying positive psychology as a whole-school approach (Norrish et al., 2013). In 2013, this was extended to the parent population through the development of a multi-component program for parents implemented at the school over an intensive 3-day period. This residential positive education program included a range of PPIs demonstrated in previous research to be effective in improving adults' positive mental health outcomes (Sin \& Lyubomirsky, 2009). Components of the program are summarised in Table 1 below. The program aimed to: (1) increase parents own understanding of wellbeing and equip them with skills to flourish, (2) allow parents and the school to develop a consistent language around wellbeing, and (3) create an opportunity to enhance the parent-school relationship by building connections with staff at the school.

\section{The current study}

Positive education programs have shown promising results in improving the wellbeing of children and adolescents (Shoshani \& Steinmetz, 2013), but to date have only engaged with parents in a limited way. The links between parent and child wellbeing and the apparent effectiveness of positive psychology interventions in adults (Duckworth, Steen, \& Seligman, 2005; Sin \& Lyubomirsky, 2009), suggest that parents could benefit from PPIs, and this may have further implications for student wellbeing. The aim of the current study was to provide preliminary insights from a small sample into the impact of the GGS Positive Education for Parents program (see Table 1 below). It was hypothesised that compared to a waitlist control group, parents participating in the program would report higher levels of wellbeing and lower levels of psychological distress, improved knowledge and use of character strengths, and more positive perceptions of their relationship with their child's school. Once parents had the opportunity to apply skills learned in the course, it was additionally hypothesised that they would report stronger connections with their children and increased child wellbeing. 
Table 1a. Components of the Positive Education for Parents program

\begin{tabular}{|c|c|c|}
\hline Session & Content & Example Activity \\
\hline $\begin{array}{l}\text { Introduction: What } \\
\text { is flourishing? }\end{array}$ & $\begin{array}{l}\text { Introduction to positive psychology, character strengths, and } \\
\text { six wellbeing domains targeted through the program: } \\
\text { emotional regulation, engagement, accomplishment of } \\
\text { meaningful goals, purpose through contribution to the } \\
\text { community, social skills for healthy relationships, and health } \\
\text { promoting behaviours }\end{array}$ & $\begin{array}{l}\text { Discussion with partner regarding character strength } \\
\text { use and future development informed by their results } \\
\text { on the Values in Action (VIA) survey } \\
\text { (www.authentichappiness.org) }\end{array}$ \\
\hline Mindfulness & Introduction to mindfulness, awareness and meditation & $\begin{array}{l}\text { Guided mindfulness meditation and reflection on this } \\
\text { experience }\end{array}$ \\
\hline $\begin{array}{l}\text { Positive } \\
\text { Accomplishment }\end{array}$ & $\begin{array}{l}\text { Discussion of ways to provide effective feedback focused on } \\
\text { effort rather than outcome ("growth mindset"; Yeager \& } \\
\text { Dweck, 2012) }\end{array}$ & $\begin{array}{l}\text { Role play providing praise focused on effort and } \\
\text { personal development rather than outcome; Reflected } \\
\text { on own fixed or growth mindsets for different domains } \\
\text { and activities in their lives }\end{array}$ \\
\hline Positive Emotions & $\begin{array}{l}\text { Discussion of the benefits of frequent displays of positive } \\
\text { emotions such as love and gratitude }\end{array}$ & $\begin{array}{l}\text { Began a "blessings journal" (Emmons \& McCullough, } \\
\text { 2003) where small or large positive events for which an } \\
\text { individual is grateful are chronicled }\end{array}$ \\
\hline $\begin{array}{l}\text { Positive } \\
\text { Relationships }\end{array}$ & $\begin{array}{l}\text { Exploring the importance of meaningful relationships to } \\
\text { wellbeing and the role of Active Constructive Responding } \\
\text { (ACR; Gable, Reis, Impett, \& Asher, 2004), attachment styles, } \\
\text { and nurturing character strengths that cultivate positive } \\
\text { relationships }\end{array}$ & $\begin{array}{l}\text { Role played ways to respond to others' good news in } \\
\text { order to deepen and broaden experience (ACR) and } \\
\text { reflected on the experience }\end{array}$ \\
\hline $\begin{array}{l}\text { Positive } \\
\text { Engagement }\end{array}$ & $\begin{array}{l}\text { Exploring the state of flow as pathway to optimal performance } \\
\text { and optimal enjoyment }\end{array}$ & $\begin{array}{l}\text { Considered how one may move an activity into a state } \\
\text { of flow by addressing the perceived skill vs challenge } \\
\text { balance }\end{array}$ \\
\hline
\end{tabular}


Table 1b. Components of the Positive Education for Parents program

\begin{tabular}{|c|c|c|}
\hline Session & Content & Example Activity \\
\hline $\begin{array}{l}\text { Positive } \\
\text { Purpose }\end{array}$ & $\begin{array}{l}\text { Exploring what provides a sense of meaning and purpose in one's } \\
\text { life and prioritizing the most important activities }\end{array}$ & $\begin{array}{l}\text { Considered key life roles and listed ways they } \\
\text { currently give to others through their actions in these } \\
\text { various roles }\end{array}$ \\
\hline $\begin{array}{l}\text { Positive } \\
\text { Health }\end{array}$ & $\begin{array}{l}\text { Explore the role of resilience and optimism in cultivating } \\
\text { flourishing, as well as physical health-promoting behaviours such } \\
\text { as sleep and nutrition }\end{array}$ & $\begin{array}{l}\text { Identified unhelpful thinking patterns, and exploring } \\
\text { evidence for unhelpful thoughts }\end{array}$ \\
\hline $\begin{array}{l}\text { Character } \\
\text { Strengths }\end{array}$ & $\begin{array}{l}\text { Exploration of character strengths and identifying novel } \\
\text { opportunities to use strengths in daily life (Seligman, Steen, Park, } \\
\text { \& Peterson, 2005) }\end{array}$ & $\begin{array}{l}\text { Discussed creative ways their signature strengths could } \\
\text { be used to overcome a challenge }\end{array}$ \\
\hline $\begin{array}{l}\text { Power of } \\
\text { Habit }\end{array}$ & $\begin{array}{l}\text { Exploration of habit as a challenge and opportunity in making } \\
\text { sustainable changes to wellbeing }\end{array}$ & $\begin{array}{l}\text { Explored the use of technology to assist forming and } \\
\text { maintaining priority habits }\end{array}$ \\
\hline Conclusion & $\begin{array}{l}\text { Summary of course content and reflection on participant's } \\
\text { experience }\end{array}$ & $\begin{array}{l}\text { Reflected on plans for implementation of new skills in } \\
\text { daily life }\end{array}$ \\
\hline
\end{tabular}




\section{Method}

\subsection{Design}

This study used a quasi-experimental design in a small sample to compare differences between scores in an intervention and a waitlist control group. Outcomes were measured at preintervention (baseline, Time 1), post intervention (Time 2), and 2 months following the program (Time 3), via online surveys. Open-ended questions were also included in the survey to produce a more comprehensive understanding of program effects (Bamberger, Rugh, \& Mabry, 2011).

\subsection{Participants}

Participants were 40 parents of children at GGS, including 24 in the intervention group and 16 in the waitlist control group (see Table 2 below for sample characteristics). Of the 62 parents invited to participate via email, the co-operation rate for the intervention and control participants was $86 \%$ and $50 \%$ respectively. The level of education attainment was higher in this sample than the Australian average, reflecting the school demographic. At baseline the intervention and control groups did not significantly differ on any of the demographic or outcome variables (see Table 2 below); suggesting that the control group provides a reasonable point of comparison.

\subsection{Measures}

Measures included scales of parent mental health, character strengths, parent-school connection, and child outcomes. Measures were chosen on the basis of previous evidence of sound validity and reliability, as well as congruence with the underlying conceptual framework, as detailed by Norrish et al. (2013).

Parent mental health. Parental wellbeing was measured with the Mental Health Continuum Short Form (MHC-SF; Keyes et al., 2008), comprising 14 items across three subscales: emotional wellbeing (e.g., "How often did you feel interested in life?"), psychological wellbeing (e.g., "How often did you feel that you had warm and trusting relationships with others?"), and social wellbeing (e.g., "How often did you feel that people are basically good?"). Participants rated the frequency of each item in the past month on a 6-point Likert scale (never, once or twice a month, about once a week, two or three times a week, almost every day, every day). The three subscales were subsequently combined to provide an overall score $(\alpha=.92)$.

Parental distress was assessed using the Kessler Psychological Distress scale (K-10; Kessler et al., 2002). The scale contains 10 items $(\alpha=.86)$ that ask participants about their level of anxiety and depressive symptoms in the past month (e.g., "In the last four weeks how often did you feel hopeless?"). The response categories for each of the 10 items range from 1 (all of the time) to 5 (none of the time).

Character strengths. The Strengths Knowledge Scale consists of eight items measuring participants recognition of their strengths on a 7-point Likert scale ranging from 1 (strongly disagree) to 7 (strongly agree) (Govindji \& Linley, 2007). Examples of items include, "I know the things I am good at doing" ( $a=.87$ ). The Strengths Use Scale (Govindji \& Linley, 2007) comprises 14 items $(\alpha=.96)$ to assess use of strengths in individuals' day-to-day lives (e.g., "Using my strengths is something I am familiar with"). Responses are indicated on a 7-point Likert scale ranging from 1 (strongly disagree) to 7 (strongly agree). 
Table 2. Baseline characteristics according to condition

\begin{tabular}{|c|c|c|c|}
\hline Variables & $\begin{array}{l}\text { Intervention } \\
\quad(\mathrm{N}=22)\end{array}$ & $\begin{array}{c}\text { Control } \\
(\mathrm{N}=11)\end{array}$ & Test Statistic \\
\hline \multicolumn{4}{|l|}{ Demographic Characteristics } \\
\hline Gender & & & $\chi^{2}=.15$ \\
\hline Male & $31.8 \%$ & $9.1 \%$ & \\
\hline Female & $68.2 \%$ & $90.9 \%$ & \\
\hline Age & & & $\chi^{2}=.19$ \\
\hline $30-39$ & $0 \%$ & $9.1 \%$ & \\
\hline $40-49$ & $59.1 \%$ & $36.4 \%$ & \\
\hline $50-59$ & $36.4 \%$ & $36.4 \%$ & \\
\hline $60+$ & $0 \%$ & $9.1 \%$ & \\
\hline Missing Data & $4.5 \%$ & $9.1 \%$ & \\
\hline Highest Education Level & & & $\chi^{2}=.13$ \\
\hline Did not complete high school & $0 \%$ & $0 \%$ & \\
\hline Graduated from high school & $0 \%$ & $0 \%$ & \\
\hline Diploma & $4.5 \%$ & $0 \%$ & \\
\hline Advanced Diploma/ Associate Degree & $9.1 \%$ & $36.4 \%$ & \\
\hline Bachelor's Degree & $72.7 \%$ & $36.4 \%$ & \\
\hline Postgraduate Degree & $9.1 \%$ & $18.2 \%$ & \\
\hline Missing Data & $4.5 \%$ & $9.1 \%$ & \\
\hline \multicolumn{4}{|l|}{ Outcome Variables (M (SD)) } \\
\hline \multicolumn{4}{|l|}{ Parent Mental Health } \\
\hline Parental Wellbeing & $47.65(13.24)$ & $50.27(8.14)$ & $t(31)=-.60, p=.55$ \\
\hline Parental Distress & $16.65(5.00)$ & $15.27(5.06)$ & $t(31)=.74, p=.46$ \\
\hline \multicolumn{4}{|l|}{ Character Strengths } \\
\hline Knowledge of Character Strengths & $42.24(3.96)$ & $40.45(8.80)$ & $t(31)=.81, p=.42$ \\
\hline Character Strengths Use & $68.59(15.34)$ & $66.64(16.19)$ & $t(31)=.34, p=.74$ \\
\hline \multicolumn{4}{|l|}{ Parent Relationship with School } \\
\hline Parent-School Connection & $20.64(3.33)$ & $20.45(3.88)$ & $t(31)=.14, p=.89$ \\
\hline \multicolumn{4}{|l|}{ Child Outcomes } \\
\hline Child Strengths & $8.23(1.90)$ & $7.91(1.81)$ & $t(31)=.46, p=.65$ \\
\hline Child Difficulties & $7.16(5.37)$ & $9.57(6.86)$ & $t(31)=-1.11, p=.28$ \\
\hline Parent-Child Relationship & $9.18(4.02)$ & $9.18(1.72)$ & $t(31)=.00, p=1.00$ \\
\hline
\end{tabular}

Parents' connection to school. Items assessing parent-school connection were drawn from the Positive School Community subscale of The Parent Questionnaire, a KidsMatter devised scale used to measure parents' perceptions about their child's school (Slee et al., 2009). Participants indicate their level of agreement with five statements about the school (e.g., "The school encourages caring relationships between staff and families" $(\alpha=.91)$. Response options ranged from 1 (strongly disagree) to 5 (strongly agree). 
Child outcomes. Child wellbeing and distress were measured according to parent reports on the Strengths and Difficulties Questionnaire (SDQ; Goodman, 1997). The SDQ is a 25-item survey that comprises five scales with five items each, answered on a 3-point Likert scale ranging from 0 (not true) to 2 (certainly true). The total difficulty score was combined ( $\alpha=.84)$ and included items from the conduct problems, hyperactivity, emotional symptoms and peer problems scales. Prosocial behaviour has been demonstrated to be an important behavioural indicator of positive mental health in childhood (Goldfeld, Kvalsvig, Incledon, O'Connor, \& Mensah, 2014; Kvalsvig et al., 2014), and hence the prosocial behaviour scale $(\alpha=.71)$ was used as a measure of child wellbeing, with items including, "In the last 6 months how often was your child kind to younger children?" (Goodman, 1997).

To assess the warmth of the parent-child relationship, participants responded to a five-item (e.g., "Most of the time, how well do you get along with your child?") adapted subscale from the Parenting Questionnaire devised by the Australian Temperament Project (Prior, Sanson, Smart, \& Oberklaid, 2000), with ratings made on a 5-point Likert scale that varied, depending on the item $(\alpha=.81$; Prior et al., 2000).

Open-ended questions. To elicit qualitative insights, participants were prompted with open questions that varied at each time point. The intervention group was asked about their motivations for attending the program at baseline. Immediately following the program, they were asked about their behaviour change intentions as well as what impact they felt this experience would have on family life. At 2-month follow-up, intervention parents were asked about the maintenance of any changes they had made, and what factors had facilitated sustained change. Control parents were asked about what schools could do to further engage parents with positive education.

\subsection{Procedure}

In 2013, GGS developed a multi-component program for parents implemented the school over an intensive 3-day period (from Friday evening to Sunday afternoon, with the intention of allowing working parents to more easily take part). This evaluation study focuses on the program conducted in July 2014 (third run). Four staff members with extensive practical experience in implementing positive education interventions facilitated the program. The program emphasized the importance of wellbeing and devoting time to building the skills for meaningful and fulfilling lives (see Table 1 above for a summary of course content). Skills were taught in plenary sessions and reinforced in small group breakout sessions that included interactive activities requiring participants to practise skills, collaborate with a partner and contribute to group discussions. At the end of each topic, participants received a short debriefing and were asked to list ways the material could be applied to their personal lives.

Data was collected using SurveyMonkey, an online survey platform. Parents eligible for the study, including those who were enrolled in the program (intervention group) and those who had indicated interest but were unable to attend on the scheduled dates (waitlist control group), were sent an email invitation to participate. Participants who consented were then directed to the 25-minute online survey at pre-program, post-program and 2-month follow-up. Waitlist participants completed the surveys at the same time as the intervention group. Data collection occurred over the period 16 June to 5 September 2014. Parents in the waitlist control condition had the opportunity to participate in a subsequent run of the program beginning after the study period. The program was implemented by the school as part of their usual practice, with no input from the evaluators. This allowed the research team to maintain an objective distance and estimate the effectiveness of the program as routinely implemented. This methodology was 
approved by the Melbourne Graduate School of Education Human Research Ethics Committee (ID number 1341289).

\subsection{Data analysis}

SPSS version 21.0 was used to conduct all analyses. In preliminary data cleaning, two outliers were recoded on strength knowledge so that they did not exert undue influence on the results (Tabachnick \& Fidell, 2013). The extent to which the program produced the expected outcomes was investigated by comparing the intervention and waitlist control group scores on the outcome variables, using 2 (Condition) by 3 (Time) mixed methods ANOVAs. Of primary interest was whether the ANOVAs showed a significant interaction effect between time (pre, post, follow-up) and condition (intervention versus control). The Huynh-Feldt correction was used to interpret findings for strengths knowledge and parental wellbeing, given the violation of the sphericity assumption (Tabachnick \& Fidell, 2013). To control for inflated rates of Type I error, the Sidak correction was used for simple comparisons. It should be noted, that given the small sample size, the results from these analyses are best considered as preliminary insights that require replication in future large-scale work.

Missing data arose where participants did not respond to the surveys at Time 2 and/or Time 3. Reasons for non-completion of surveys included participants unable to be contacted, and unavailability due to some data collection occurring during the school holidays. Participants were excluded from the analyses if they provided baseline data only ( 2 intervention and 5 control; see Table 3 below), leading to a final sample of $n=22$ intervention and $n=11$ control participants. To reduce potential sampling bias and reduction of statistical power, the Expectation-Maximisation method (Raghunathan, 2004) was used to impute missing data for remaining participants. These analyses were also run using complete case analyses and regression replacement. Findings were consistent across these approaches and would not change study conclusions, suggesting that the choice of imputation did not have an undue influence on the findings.

Table 3. Response to each wave of the survey for intervention and control participants

\begin{tabular}{lccc}
\hline Participants & Time 1 & Time 2 & Time 3 \\
& N (\%) & N (\%) & N (\%) \\
\hline Control & $16(100)$ & $10(62.5)$ & $10(62.5)$ \\
Intervention & $24(100)$ & $21(87.5)$ & $20(83.0)$ \\
\hline
\end{tabular}

Qualitative analysis was conducted on responses to the open-ended questions in order to measure parents' perceptions of the Positive Education program, both as a means to enrich understanding of the program impact and to understand how participants experienced the program. Thematic analysis was used, based on the method proposed by Braun and Clark (2006), which provides an account of the data, through the process of extracting common themes and drawing meaning from the written responses in a way that contributes to the understanding of the event. Responses were analysed and coded according to their meaning, and common themes were extracted. 
Table 4. Descriptive statistics and ANOVA results

\begin{tabular}{|c|c|c|c|c|c|c|c|c|c|}
\hline \multirow{2}{*}{ Variable } & \multicolumn{3}{|c|}{ Control M(SD) } & \multicolumn{3}{|c|}{ Intervention M(SD) } & \multirow{2}{*}{ Main Effect } & \multirow{2}{*}{$\begin{array}{c}\text { Between } \\
\text { Subjects Effect }\end{array}$} & \multirow{2}{*}{$\begin{array}{c}\text { Interaction } \\
\text { Effect }\end{array}$} \\
\hline & T1 & $\mathrm{T} 2$ & T3 & T1 & T2 & T3 & & & \\
\hline Parental Wellbeing & $\begin{array}{l}50.27 \\
(8.14)\end{array}$ & $\begin{array}{c}49.55 \\
(11.66)\end{array}$ & $\begin{array}{c}47.73 \\
(14.93)\end{array}$ & $\begin{array}{c}47.65 \\
(13.24)\end{array}$ & $\begin{array}{c}51.86 \\
(11.18)\end{array}$ & $\begin{array}{l}54.57 \\
(9.53)\end{array}$ & $\begin{array}{c}F(1,21)=.86 \\
p=.42, \eta_{p^{2}}=.03\end{array}$ & $\begin{array}{c}F(1,21)=.34 \\
p=.57, \eta_{\mathrm{p}}^{2}=.01\end{array}$ & $\begin{array}{c}F(1,21)=.3 .59 \\
p=.04, \eta_{\mathrm{p}}^{2}=.10\end{array}$ \\
\hline Parental Distress & $\begin{array}{l}15.27 \\
(5.06)\end{array}$ & $\begin{array}{l}15.24 \\
(4.54)\end{array}$ & $\begin{array}{l}15.73 \\
(5.57)\end{array}$ & $\begin{array}{l}16.65 \\
(5.0)\end{array}$ & $\begin{array}{l}15.03 \\
(3.99)\end{array}$ & $\begin{array}{l}13.57 \\
(2.20)\end{array}$ & $\begin{array}{l}F(1,21)=.1 .62 \\
p=.21, \eta_{\mathrm{p}}^{2}=.05\end{array}$ & $\begin{array}{c}F(1,21)=.06 \\
p=.81, \eta_{\mathrm{p}}{ }^{2}=.00\end{array}$ & $\begin{array}{l}F(1,21)=.2 .89 \\
p=.06, \eta_{\mathrm{p}}^{2}=.09\end{array}$ \\
\hline $\begin{array}{l}\text { Knowledge of } \\
\text { Character Strengths }\end{array}$ & $\begin{array}{l}40.45 \\
(8.80)\end{array}$ & $\begin{array}{l}39.96 \\
(9.30)\end{array}$ & $\begin{array}{l}44.09 \\
(6.52)\end{array}$ & $\begin{array}{l}42.24 \\
(3.96)\end{array}$ & $\begin{array}{l}43.10 \\
(6.25)\end{array}$ & $\begin{array}{l}44.48 \\
(3.79)\end{array}$ & $\begin{array}{l}F(1,21)=.2 .60 \\
p=.09, \eta_{\mathrm{p}}^{2}=.08\end{array}$ & $\begin{array}{l}F(1,21)=.1 .32 \\
p=.26, \eta_{p}^{2}=.04\end{array}$ & $\begin{array}{c}F(1,21)=.45 \\
p=.61, \eta_{\mathrm{p}}^{2}=.01\end{array}$ \\
\hline $\begin{array}{l}\text { Character Strengths } \\
\text { Use }\end{array}$ & $\begin{array}{c}66.64 \\
(16.19)\end{array}$ & $\begin{array}{c}67.24 \\
(17.30)\end{array}$ & $\begin{array}{c}72.64 \\
(16.73)\end{array}$ & $\begin{array}{c}68.59 \\
(15.34)\end{array}$ & $\begin{array}{c}73.29 \\
(14.36)\end{array}$ & $\begin{array}{c}77.05 \\
(12.06)\end{array}$ & $\begin{array}{l}F(1,21)=.3 .04 \\
p=.06, \eta_{p}^{2}=.09\end{array}$ & $\begin{array}{c}F(1,21)=.92 \\
p=.35, \eta_{\mathrm{p}}=.03\end{array}$ & $\begin{array}{c}F(1,21)=.24, \\
p=.79, \eta_{\mathrm{p}}^{2}=.00\end{array}$ \\
\hline Parent-School & 20.45 & 19.67 & 19.90 & 20.64 & 22.20 & 21.40 & $F(1,21)=.55$ & $F(1,21)=1.60$ & $F(1,21)=4.71$ \\
\hline Connection & $(3.88)$ & $(4.02)$ & $(4.11)$ & $(3.33)$ & $(2.36)$ & $(2.63)$ & $p=.59, \eta_{\mathrm{p}}{ }^{2}=.02$ & $p=.27, \eta_{p}^{2}=.05$ & $p=.01, \eta_{p}^{2}=.13$ \\
\hline Parent-Child & 15.82 & 15.71 & 16.09 & 15.81 & 15.76 & 16.18 & $F(1,21)=.73$ & $F(1,21)=.00$ & $F(1,21)=.01$ \\
\hline Connection & $(1.72)$ & $(2.83)$ & $(2.39)$ & $(4.02)$ & $(3.82)$ & $(3.79)$ & $p=.48, \eta_{p^{2}}=.02$ & $p=.97, \eta_{p}^{2}=.00$ & $p=.99, \eta_{p}^{2}=.00$ \\
\hline Child Strength & $\begin{array}{r}7.91 \\
(1.81)\end{array}$ & $\begin{array}{c}8.10 \\
(1.45)\end{array}$ & $\begin{array}{c}8.93 \\
(1.50)\end{array}$ & $\begin{array}{c}8.23 \\
(1.90)\end{array}$ & $\begin{array}{c}7.96 \\
(1.89)\end{array}$ & $\begin{array}{c}8.03 \\
(1.98)\end{array}$ & $\begin{array}{l}F(1,21)=.1 .88 \\
p=.16, \eta_{p^{2}}=.06\end{array}$ & $\begin{array}{c}F(1,21)=.16 \\
p=.69, \eta_{p}=.01\end{array}$ & $\begin{array}{l}F(1,21)=.2 .90 \\
p=.06, \eta_{\mathrm{p}}^{2}=.09\end{array}$ \\
\hline Child Difficulty & $\begin{array}{r}9.57 \\
(6.86) \\
\end{array}$ & $\begin{array}{r}7.34 \\
(6.72) \\
\end{array}$ & $\begin{array}{r}8.13 \\
(5.54) \\
\end{array}$ & $\begin{array}{r}7.16 \\
(5.37) \\
\end{array}$ & $\begin{array}{r}6.85 \\
(5.98) \\
\end{array}$ & $\begin{array}{r}5.81 \\
(4.47) \\
\end{array}$ & $\begin{array}{l}F(1,21)=.2 .50 \\
p=.09, \eta_{p^{2}}=.08\end{array}$ & $\begin{array}{c}F(1,21)=.38 \\
p=.03^{*}, \eta_{p^{2}}=.03\end{array}$ & $\begin{array}{l}F(1,21)=.1 .24 \\
p=.30, \eta_{\mathrm{p}}{ }^{2}=.08\end{array}$ \\
\hline
\end{tabular}




\section{Results}

\subsection{Quantitative evaluation}

Intervention and control participants did not significantly differ on outcomes measured at baseline (Table 2 above). Levels of some outcomes were already high at baseline; for example, mean levels of child strengths were $M=8.23$ for the intervention and $M=7.91$ for the control group, out of a possible 10. This suggests that the control group may be used as a point of comparison, although, as discussed in a later section, the sample size and ceiling effects should be considered. Correlations between the outcome variables (not shown) ranged from weak to moderate, and were strongest between character strengths knowledge and use $(r=.69, p<.001)$ and parent-child warmth and child wellbeing $(r=.69, p<.001)$.

The extent to which the positive education program for parents produced the hypothesised outcomes was investigated by comparing the intervention and control group scores at each time point on the outcome variables. The results of ANOVAs revealed significant interaction effects for parental wellbeing and parent-school connection, suggesting that there were measurable differences between the intervention and control group from pre- to post-intervention on these outcomes (see Table 4 above). No significant interaction effects were observed in relation to knowledge or use of character strengths, parental distress, warmth of the parent-child relationship, or parents' perceptions of their child's strengths and difficulties.

A significant group by time interaction was observed for parental wellbeing (Table 4 above). Simple comparisons showed that compared to pre-intervention, participants in the intervention group had significantly higher mean wellbeing at post-intervention $\left(F(1,21)=9.73, p=.01, \eta_{\mathrm{p}}^{2}=.32\right)$, and also at 2-month follow-up $\left(F(1,21)=9.34, p=.01, \eta_{p}^{2}=.31\right)$, as illustrated in Figure 1 below. These findings suggest that parental wellbeing tended to increase as a function of participating in the intervention.

Figure 1. Change over time in parental wellbeing according to condition type. Error bars show one standard deviation.

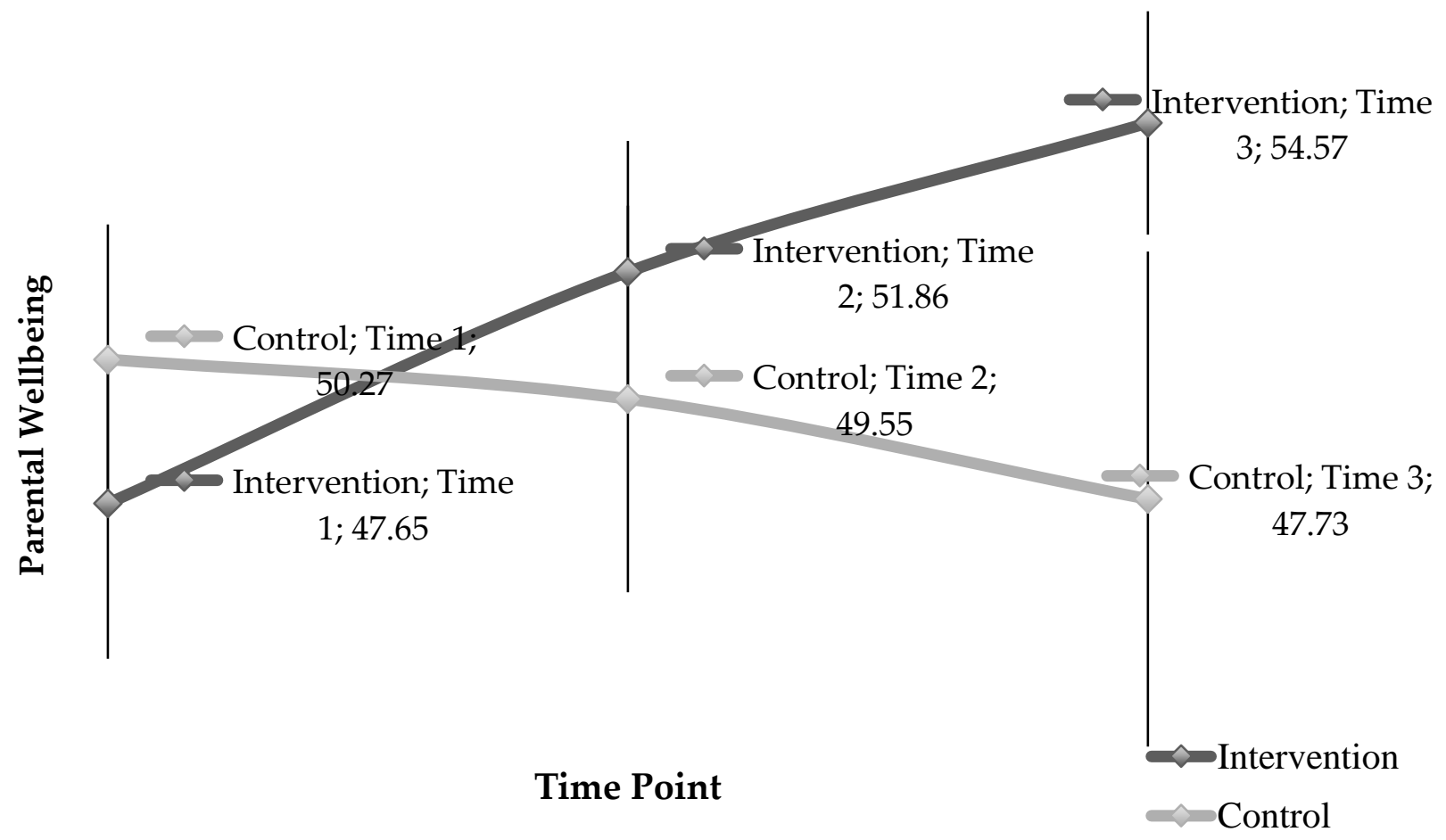


A significant group by time interaction for parent-school connection was also observed (see Table 4 above). Simple comparisons demonstrated significant improvements in parent-school connection at post-intervention compared to pre-intervention $\left(F(1,21)=13.25, p=.01, \eta_{\mathrm{p}}^{2}=.39\right)$, with a medium-sized effect. However, as displayed in Figure 2 below, by the 2-month follow-up, parents who participated in the positive education program did not have a significantly higher mean than at pre-test $\left(F(1,21)=2.61, p=.12, \eta_{\mathrm{p}}{ }^{2}=.11\right)$.

Figure 2. Change over time in parent-school connection according to condition. Error bars show one standard deviation.

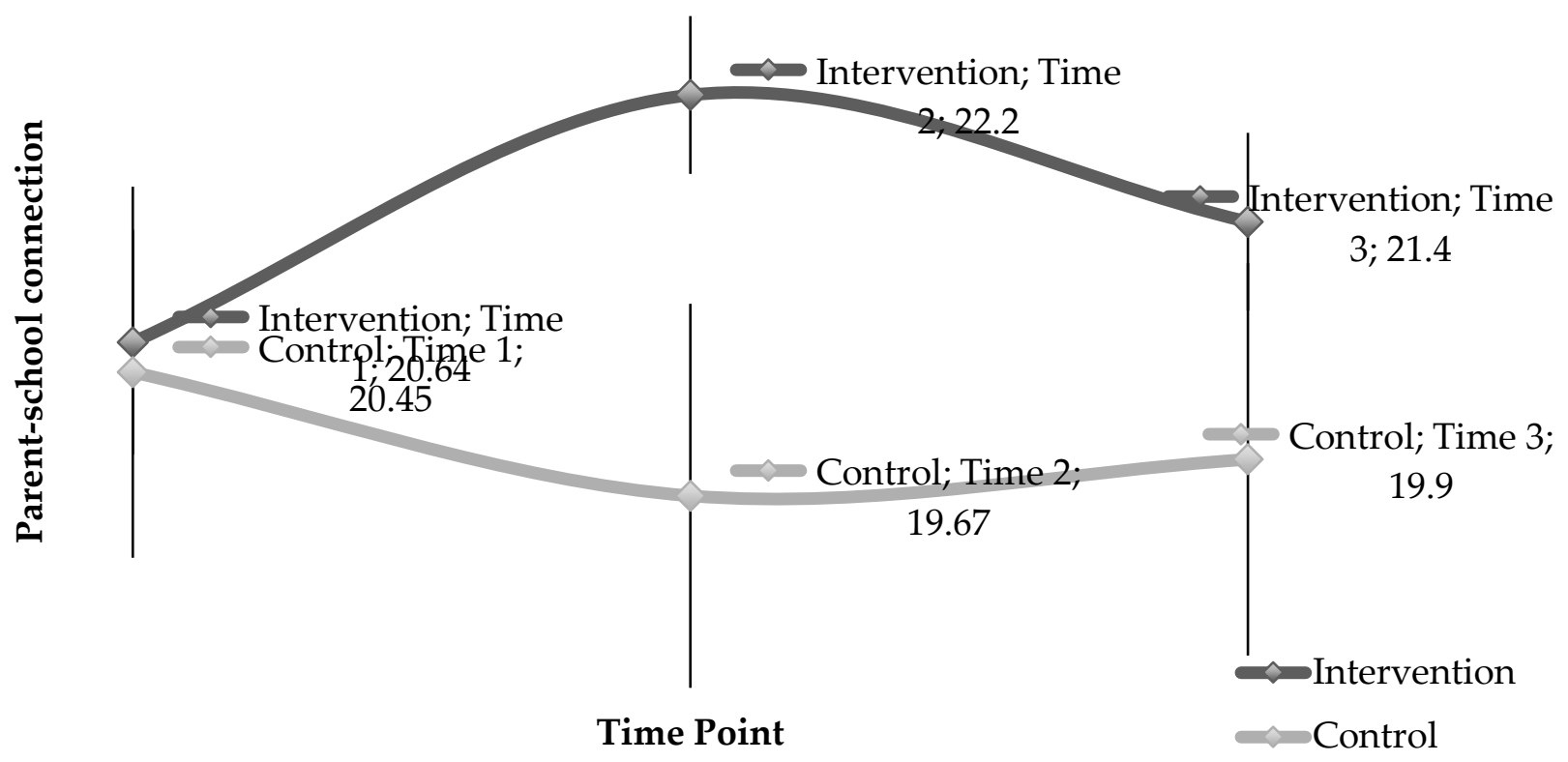

\subsection{Qualitative themes}

In the analysis of written parent responses to open-ended questions in the survey at each time point, three consistent themes were evident.

Increased understanding of positive education. 20 out of 23 parents who participated in the program reported on the survey that they developed a greater understanding of positive education through this experience, for example, "... it certainly deepened my understanding of the concepts being presented to the children and my ability to support these concepts through my parenting in the home." At pre-intervention, parents reported that a key reason for attending the program was to increase their knowledge of positive education, and to learn how to apply these skills at home with their children. At post-intervention, parents reported that they had learned new concepts and skills (such as mindfulness, keeping a gratitude journal), and at 2month follow-up most parents reported that they had incorporated at least one of these strategies into their daily lives (e.g., "I find myself looking out for those [Active Constructive Responding] moments and opportunities to share a moment of closeness").

Shared language around wellbeing. At post-intervention, 12 out of 23 parents reported that the knowledge obtained from the program helped to develop a shared language around wellbeing with their children (e.g., "...I now have the same [positive education] language as her. It can be funny sometimes but mostly we enhance each other's understanding of a situation..."). Parents reported that their explicit knowledge of course content provided stimulus for conversation with their children; for example, “...better shared understanding and key concepts and words to work with in supporting the school program." Parents indicated that the program gave them a 
language to discuss wellbeing in a collaborative way, and provided terminology to reinforce the school's teachings, which in turn increased communication with their children. For example, following the program one parent reported, "I can tune in to how he may respond, based on the information that I know he has absorbed and may be working with." Additionally, parents believed that the program's content, specifically, ACR, process praise and maintaining positive emotion, enhanced the quality of their communication with their children.

Parent-school connection. Reinforcing the quantitative findings, 18 out of 23 parents reported a greater sense of connection to the school and more positive perceptions of their place within the school community following the program. Seventy-eight percent of parents described viewing the school more positively and feeling greater appreciation of their place in the school community (e.g., "deepened my sense of being part of a community"). Parents reported that the program built positive relationships with school staff (e.g., "engagement with the teachers has opened up a whole new world").

Finally, 10 parents in the control condition provided ideas regarding other possible ways to engage parents with positive education, including online reading material, attending their child's positive education class, providing examples of how to use positive education at home, and including positive education on school reports.

\section{Discussion}

This small-scale study examined the impact of a positive education program for parents implemented within a whole-school positive education framework. While further research is needed to replicate findings in larger samples, the data revealed measurable increases in levels of wellbeing and connectedness to the school for those parents who participated in the program, compared to a waitlist control group. Overall, these findings provide promising preliminary indications of the potential benefits of engaging parents in positive education, as well as suggesting opportunities for program development. In particular, sustaining change is a challenge in many programs and appears to be an important consideration for further program development. Future larger-scale evaluation appears warranted.

Participation in the Positive Education for Parents program was associated with increased levels of wellbeing at post-intervention, which was sustained at 2-month follow-up. Previous research with adults has demonstrated that positive psychology interventions can be effective in producing improvements in wellbeing (Lyubomirsky, Sheldon, \& Schkade, 2005), and these findings suggest that PPIs may be just as relevant for parents as for other key stakeholders in the school community. A sustained improvement in parental wellbeing is an important outcome in its own right, but is particularly important, given the proximal influence that parents have on their child's development (Bronfenbrenner, 1979), and the links between parental wellbeing and child wellbeing (Ehrmantrout et al., 2011; Ma \& Huebner, 2008).

Parents also reported a greater sense of connection to the school immediately following the program, compared with the parents in the control group, however, this was not maintained at follow-up. There are a number of possible explanations for this. It may be that the school's efforts to include parents gave a greater sense of being valued within the school community, or it may be that increasing parent understanding of the program allowed parents to feel more connected to and use the conceptual language of the school program more effectively (Shoshani \& Steinmetz, 2013; Suldo et al., 2012). In particular, qualitative data indicated that parents experienced high-quality parent-teacher and parent-parent interactions during the program, characterised by respect, trust and reciprocity, and developed a shared understanding about the importance of positive education for themselves and their children. This positive effect on the 
parent-school relationship was no longer evident at 2-month follow-up, indicating that there may be a need for further ongoing opportunities for parents to be engaged and involved to sustain this change (Epstein, 2011; Suldo et al., 2012).

The lack of significant effects observed in relation to other outcomes also warrants consideration. It is difficult to rule out whether the lack of significant effects observed in relation to the other outcome measures was due to the lack of actual effects, or the small sample size which limited the capacity to detect them. It is interesting to note that while no quantitative improvement in the warmth of the parent-child relationship was observed, parents' qualitative reports at 2-month follow-up indicated that they believed participation in the program lead to higher quality interactions and communication with their children, suggesting that the parentchild relationship may have changed, but in different ways than those measured quantitatively. Parents in the intervention group additionally did not report improvements in children's strengths and difficulties; it is possible that the new practices implemented by parents may take longer than the current 2-month follow-up period before their children can reap the benefits, and a longer term follow-up should be considered in future evaluation efforts. Alternately, ways in which these skills can be utilised in the family setting may need to be directly addressed in the program to achieve changes on these outcomes. The lack of observed increases in strength knowledge or strength use is in line with research that suggests it may be necessary to move beyond an "identify and use" approach to a "strengths development" approach, which involves learning what character strengths to use and how often, when given specific situational or social influences (Biswas-Diener, Kashdan, \& Minhas, 2011).

\subsection{Strengths and limitations}

Several aspects of the design of this study are worth considering replicating in future larger-scale evaluation efforts. The mixed method design combines quantitative data to measure program outcomes and qualitative data to understand participant experiences of the program. The use of a waitlist control group strengthened the likelihood that both groups would be similar on measured and non-measured variables. As such, the control group provided an important point of comparison; indeed, it was observed that the control group's scores varied on a number of outcome variables over time, indicating the importance of creating a well-matched control group in future research.

Despite these strengths, results should nevertheless be interpreted as preliminary, with the study being best conceptualised as a preliminary investigation that can inform future larger-scale evaluation efforts. The small sample size provided limited power to detect effects, and, as such, future research with a larger sample is needed, to reduce the probability of Type 1 and 2 error. In addition, the sample used in this study was fairly homogenous, involving parents from one high socioeconomic status school only, and included a small group of parents that may have had particular characteristics that led them to nominate for the program. Care should therefore be taken in extrapolating the findings, and future work would benefit from a larger sample from a number of diverse school settings, with a broader set of measures to be applied to multiple informants, such as students and teachers. Finally, a longer follow-up period would allow for greater likelihood of detecting flow-on effects for student wellbeing, if these are occurring.

\subsection{Future Directions}

Results of this evaluation provide preliminary evidence that positive education could be associated with benefits for parents' wellbeing and their connection to their child's school, suggesting that further larger-scale evaluation efforts are worthwhile. A number of ways in 
which the current findings could usefully inform the design of future investigations have been suggested. In addition, future evaluation efforts may benefit from comparing a number of possible training models: this program was run as an intensive workshop, but further research may reveal other potential implementation strategies that could be used for parents with busy work and childcare commitments, such as weekly evening sessions across a school term. Adopting a more sustained approach in comparison to an intensive format has demonstrated greater efficacy in previous research, as participants have more time to learn and implement new skills (Froh et al., 2014).

These preliminary results also indicate a number of potential areas for further program development. No program effects were observed in relation to child outcomes, which may be more likely to occur if the program's content specifically addresses the links between parent and child wellbeing, including explicit instruction of how parents can apply the positive education content and their newly acquired skills to enhance family functioning and set goals to build family strengths (Suldo \& Fefer, 2013). To assist parents in maintaining desired changes, schools could run booster sessions where parents who have attended the positive education program could interact with staff to discuss their achievements and obstacles (Suldo et al., 2012).

Positive education programs for parents are likely to be of most benefit to the school community if parent uptake in the program is high. Only a small proportion of parents across the full school community took up the opportunity to engage in the program, which is consistent with reports of other school-based programs targeting children's health and development (Axford, Lehtonen, Kaoukji, Tobin, \& Berry, 2012; Garcia-Dominic et al., 2010; Heinrichs, Bertram, Kuschel, \& Hahlweg, 2005). To ensure that parents perceive participation in positive education programs as useful, promotion of the program should capture parents' main motivations for participating. In this group, qualitative findings suggest that parents were seeking increased understanding of positive education in order to provide greater support to their children.

\section{Conclusions}

Interest in positive education as a framework for promoting wellbeing within school communities is growing. However, there has been limited research to guide effective engagement of the parent population with positive education. This small-scale study provides valuable preliminary insights into the impact of one potential avenue of involving parents, focusing on an intensive workshop where parents learn about and apply previously validated positive psychology interventions. The results revealed observable changes in parents' wellbeing and their feelings of connectedness to the school following participation in the Positive Education for Parents program. These preliminary findings suggest that further larger-scale evaluation efforts will be useful to establish the most effective ways to purposefully and strategically engage parents in whole-school positive education programs.

\section{Acknowledgements}

We wish to sincerely thank all parents who generously contributed their time and insights to this project. We are also grateful to key staff at Geelong Grammar School who assisted in facilitating the program evaluation, including Justin Robinson and Janis Coffey.

\section{Conflict of Interest Statement}

Meredith O'Connor is an employee of Geelong Grammar School. 


\section{Authors}

Karina Dubroja

The University of Melbourne

karina.dubroja@gmail.com

Meredith O'Connor

The University of Melbourne

Vicki Mckenzie

The University of Melbourne

\section{Publishing Timeline}

Received 20 July 2015

Accepted 21 July 2016

Published 14 October 2016

\section{References}

Australian Curriculum Assessment and Reporting Authority. (2013). General capabilities in the Australian curriculum. http://www.australiancurriculum.edu.au/generalcapabilities/personal-and-socialcapability/introduction/introduction

Axford, N., Lehtonen, M., Kaoukji, D., Tobin, K., \& Berry, V. (2012). Engaging parents in parenting programs: Lessons from research and practice. Children and Youth Services Review, 34(10), 2061-2071. http://dx.doi.org/10.1016/j.childyouth.2012.06.011

Bamberger, M., Rugh, J., \& Mabry, L. (2011). RealWorld evaluation: Working under budget, time, data, and political constraints. London, England: Sage.

Betts, J., Gullone, E., \& Allen, J. S. (2009). An examination of emotion regulation, temperament, and parenting style as potential predictors of adolescent depression risk status: A correlational study. British Journal of Developmental Psychology, 27(2), 473-485. http://dx.doi.org/10.1348/026151008X314900

Biswas-Diener, R., Kashdan, T. B., \& Minhas, G. (2011). A dynamic approach to psychological strength development and intervention. The Journal of Positive Psychology, 6(2), 106-118. http://dx.doi.org/10.1080/17439760.2010.545429

Bronfenbrenner, U. (1979). The ecology of human development. Cambridge, MA: Harvard University Press.

Bruce, A. E., Cole, D. A., Dallaire, D. H., Jacquez, F. M., Pineda, A. Q., \& LaGrange, B. (2006). Relations of parenting and negative life events to cognitive diatheses for depression in children. Journal of Abnormal Child Psychology, 34(3), 310-322. http://dx.doi.org/10.1007/s10802-006-9019-x

Casas, F., Coenders, G., González, M., Malo, S., Bertran, I., \& Figuer, C. (2012). Testing the relationship between parents' and their children's subjective well-being. Journal of Happiness Studies, 13(6), 10311051. http://dx.doi.org/10.1007/s10902-011-9305-3

Crosby, B. M., Drazdowski, T. K., \& Ginsburg, G. S. (2013). Anxiety-promoting parenting behaviors: A comparison of anxious parents with and without social anxiety disorder. Child Psychiatry \& Human Development, 44(3), 412-418. http://dx.doi.org/10.1007/s10578-012-0335-9

Danielsen, A. G., Samdal, O., Hetland, J., \& Wold, B. (2009). School-related social support and students' perceived life satisfaction. The Journal of Educational Research, 102(4), 303-320. http://dx.doi.org/10.3200/JOER.102.4.303-320

Duckworth, A., Steen, T., \& Seligman, M. (2005). Positive psychology in clinical practice. Annual Review of Clinical Psychology, 1, 629-651. http://dx.doi.org/10.1146/annurev.clinpsy.1.102803.144154

Ehrmantrout, N., Allen, N. B., Leve, C., Davis, B., \& Sheeber, L. (2011). Adolescent recognition of parental affect: Influence of depressive symptoms. Journal of Abnormal Psychology, 120(3), 628-634. http://dx.doi.org/10.1037/a0022500 
Emmons, R. A., \& McCullough, M. E. (2003). Counting blessings versus burdens: An experimental investigation of gratitude and subjective well-being in daily life. Journal of Personality and Social Psychology, 84(2), 377-389. http://dx.doi.org/10.1037/0022-3514.84.2.377

Epstein, J. L. (1995). School/family/community partnerships: Caring for the children we share. Phi Delta Kappan, 76(9), 701-712.

Epstein, J. L. (2011). School, family, and community partnerships: Preparing educators and improving schools. (2nd ed.). Philadelphia, PA: Westview Press.

Froh, J., Bono, G., Emmons, R., Wood, A., Henderson, K., Fan, J., \& Leggio, H. (2014). Nice thinking! An educational intervention that teaches children how to think gratefully. School Psychology Review, 43(2), 132-152.

Gable, S. L., Reis, H. T., Impett, E. A., \& Asher, E. R. (2004). What do you do when things go right? The intrapersonal and interpersonal benefits of sharing positive events. Journal of Personality and Social Psychology, 87(2), 228-245. http://dx.doi.org/10.1037/0022-3514.87.2.228

Garcia-Dominic, O., Wray, L. A., Treviño, R. P., Hernandez, A. E., Yin, Z., \& Ulbrecht, J. S. (2010). Identifying barriers that hinder onsite parental involvement in a school-based health promotion program. Health Promotion Practice, 11(5), 703-713. http://dx.doi.org/10.1177/1524839909331909

Goldfeld, S., Kvalsvig, A., Incledon, E., O'Connor, M., \& Mensah, F. (2014). Predictors of mental health competence in a population cohort of Australian children. Journal of Epidemiology and Community Health, 68(5), 431-437. http://dx.doi.org/10.1136/jech-2013-203007

Goodman, R. (1997). The strengths and difficulties questionnaire: A research note. Journal of Child Psychology and Psychiatry, 38(5), 581-586. http://dx.doi.org/10.1111/j.1469-7610.1997.tb01545.x

Govindji, R., \& Linley, P. A. (2007). Strengths use, self-concordance and well-being: Implications for strengths coaching and coaching psychologists. International Coaching Psychology Review, 2(2), 143153.

Heinrichs, N., Bertram, H., Kuschel, A., \& Hahlweg, K. (2005). Parent recruitment and retention in a universal prevention program for child behavior and emotional problems: Barriers to research and program participation. Prevention Science, 6(4), 275-286. http://dx.doi.org/10.1007/s11121-005-0006-1

Hoy, B., Suldo, S., \& Mendez, L. (2013). Links between parents' and children's levels of gratitude, life satisfaction, and hope. Journal of Happiness Studies, 14(4), 1343-1361. http://dx.doi.org/10.1007/s10902$\underline{012-9386-7}$

Huppert, F. A., Abbott, R. A., Ploubidis, G. B., Richards, M., \& Kuh, D. (2010). Parental practices predict psychological well-being in midlife: Life-course associations among women in the 1946 British birth cohort. Psychological Medicine, 40(9), 1507-1518. http://dx.doi.org/10.1017/S0033291709991978

Jaser, S. S., Langrock, A. M., Keller, G., Merchant, M. J., Benson, M. A., Reeslund, K., . . Compas, B. E. (2005). Coping with the stress of parental depression II: Adolescent and parent reports of coping and adjustment. Journal of Clinical Child \& Adolescent Psychology, 34(1), 193-205. http://dx.doi.org/10.1207/s15374424jccp3401 18

Kessler, R. C., Andrews, G., Colpe, L. J., Hiripi, E., Mroczek, D. K., Normand, S.-L., . . Zaslavsky, A. M. (2002). Short screening scales to monitor population prevalences and trends in non-specific psychological distress. Psychological Medicine, 32(6), 959-976. http://dx.doi.org/10.1017/S0033291702006074

Keyes, C. L. M., Wissing, M., Potgieter, J. P., Temane, M., Kruger, A., \& van Rooy, S. (2008). Evaluation of the mental health continuum-short form (MHC-SF) in Setswana-speaking South Africans. Clinical Psychology \& Psychotherapy, 15(3), 181-192. http://dx.doi.org/10.1002/cpp.572

Knappe, S., Beesdo-Baum, K., Fehm, L., Lieb, R., \& Wittchen, H. (2012). Characterizing the association between parenting and adolescent social phobia. Journal of Anxiety Disorders, 26(5), 608-616. http://dx.doi.org/10.1016/j.janxdis.2012.02.014

Kvalsvig, A., O'Connor, M., Redmond, G., \& Goldfeld, S. (2014). The unknown citizen: Epidemiological challenges in child mental health. Journal of Epidemiology and Community Health, 68, 1004-1008. http://dx.doi.org/10.1136/jech-2013-203712 
Lyubomirsky, S., Sheldon, K. M., \& Schkade, D. (2005). Pursuing happiness: The architecture of sustainable change. Review of General Psychology, 9(2), 111-131. http://dx.doi.org/10.1037/10892680.9.2.111

Ma, C. Q., \& Huebner, E. S. (2008). Attachment relationships and adolescents' life satisfaction: Some relationships matter more to girls than boys. Psychology in the Schools, 45(2), 177-190. http://dx.doi.org/10.1002/pits.20288

Norrish, J., \& O'Connor, M. (2015). Research and evaluation. In J. M. Norrish (Ed.), Positive education: The Geelong Grammar School journey (pp. 275-288). Oxford, England: Oxford University Press. http://dx.doi.org/10.1093/acprof:oso/9780198702580.003.0013

Norrish, J., Williams, P., O'Connor, M., \& Robinson, J. (2013). An applied framework for positive education. International Journal of Wellbeing, 3(2), 147-161.

O'Connor, M., Sanson, A., Hawkins, M., Letcher, P., Toumbourou, J., Smart, D., . . Olsson, C. (2011). Predictors of positive development in emerging adulthood. Journal of Youth and Adolescence, 40(7), 860-874. http://dx.doi.org/10.1007/s10964-010-9593-7

Park, N., \& Peterson, C. (2006). Moral competence and character strengths among adolescents: The development and validation of the Values in Action Inventory of Strengths for Youth. Journal of Adolescence, 29(6), 891-909. http://dx.doi.org/10.1016/j.adolescence.2006.04.011

Prior, M. R., Sanson, A., Smart, D., \& Oberklaid, F. (2000). Pathways from infancy to adolescence: Australian Temperament Project 1983-2000. Melbourne, Australia: Australian Institute of Family Studies.

Raghunathan, T. (2004). What do we do with missing data? Some options for analysis of incomplete data. Annual Review of Public Health, 25, 99-117. http://dx.doi.org/10.1146/annurev.publhealth.25.102802.124410

Schwarz, B., Mayer, B., Trommsdorff, G., Ben-Arieh, A., Friedlmeier, M., Lubiewska, K., . . Peltzer, K. (2011). Does the importance of parent and peer relationships for adolescents' life satisfaction vary across cultures? The Journal of Early Adolescence, 32(1), 55-80. http://dx.doi.org/10.1177/0272431611419508

Seligman, M., Ernst, R., Gillham, J., Reivich, K., \& Linkins, M. (2009). Positive education: Positive psychology and classroom interventions. Oxford Review of Education, 35, 293-311. http://dx.doi.org/10.1080/03054980902934563

Seligman, M., Steen, T., Park, N., \& Peterson, C. (2005). Positive psychology progress: Empirical validation of interventions. American Psychologist, 60(5), 410-421. http://dx.doi.org/10.1037/0003$\underline{066 X .60 .5 .410}$

Shoshani, A., \& Steinmetz, S. (2013). Positive psychology at school: A school-based intervention to promote adolescents' mental health and well-being. Journal of Happiness Studies, 1-23.

Siddall, J., Huebner, E. S., \& Jiang, X. (2013). A prospective study of differential sources of school-related social support and adolescent global life satisfaction. American Journal of Orthopsychiatry, 83(1), 107114. http://dx.doi.org/10.1111/ajop.12006

Sin, N. L., \& Lyubomirsky, S. (2009). Enhancing well-being and alleviating depressive symptoms with positive psychology interventions: A practice-friendly meta-analysis. Journal of Clinical Psychology, 65(5), 467-487. http://dx.doi.org/10.1002/jclp.20593

Slee, P. T., Lawson, M. J., Russell, A., Askell-Williams, H., Dix, K. L., Owens, L. D., . . Spears, B. (2009). KidsMatter primary evaluation final report: Adelaide, Australia: Flinders University.

Suldo, S., \& Fefer, S. (2013). Parent-child relationships and well-being. In C. Proctor \& P. A. Linley (Eds.), Research, Applications, and Interventions for Children and Adolescents (pp. 131-147). Dordrecht, The Netherlands: Springer. http://dx.doi.org/10.1007/978-94-007-6398-2 8

Suldo, S., McMahan, M., Chappel, A., \& Loker, T. (2012). Relationships between perceived school climate and adolescent mental health across genders. School Mental Health, 4(2), 69-80.

http://dx.doi.org/10.1007/s12310-012-9073-1

Tabachnick, B. G., \& Fidell, L. S. (2013). Using Multivariate Statistics (6th ed.). Boston, MA: Pearson International.

Vella-Brodrick, D., Rickard, N., \& Chin, T. (2014). An evaluation of positive education at Geelong Grammar School: A snapshot of 2013. Melbourne, Australia: The University of Melbourne. 
Viner, R. M., Ozer, E. M., Denny, S., Marmot, M., Resnick, M., Fatusi, A., \& Currie, C. (2012). Adolescence and the social determinants of health. The Lancet, 379(9826), 1641-1652. http://dx.doi.org/10.1016/S0140-6736(12)60149-4

Waters, L. (2011). A review of school-based positive psychology interventions. The Australian Educational and Developmental Psychologist, 28(2), 75-90. http://dx.doi.org/10.1375/aedp.28.2.75

White, J. (2011). Exploring well-being in schools. Abingdon, England: Routledge.

Yeager, D. S., \& Dweck, C. S. (2012). Mindsets that promote resilience: When students believe that personal characteristics can be developed. Educational Psychologist, 47(4), 302-314.

http://dx.doi.org/10.1080/00461520.2012.722805 